\title{
MATHEMATICAL MODEL OF HEAT TRANSFER IN MORPHOLOGICAL PART OF VEGETATION AT INFLUENCE BY THERMAL RADIATION FROM SURFACE FOREST FIRE FRONT
}

\author{
Nikolay V. Baranovskiy ${ }^{1, *}$, and Alena N. Demikhova ${ }^{1}$ \\ ${ }^{1}$ National Research Tomsk Polytechnic University, 634050 Tomsk, Russia
}

\begin{abstract}
Numerical research results of heat transfer in layered tree trunk influenced by heat flux from forest fire are presented. The problem is solved in two-dimensional statement in Cartesian system of co-ordinates. The typical range of influence parameters of heat flux from forest fire is considered. Temperature distributions in different moments of time are obtained. Condition of tree damage by forest fire influence is under consideration in this research.
\end{abstract}

\section{Introduction}

There are few growing plant layers in forest depending on biological features of the major plants, their age and certain physical-geographical conditions. Each layer - accurately enough delimited horizons of active plant parts concentration. Layers can be formed by plants of one or two and more types. Following layers can be distinguished in forest [1]:

- Forest stand. Crown layer is set of crones of the closed trees. Two crown layers can be marked out in moderate forests, but five crown layers can be differentiated in tropical forests. There is layer of very high trees towering over crown layer of forest stand in tropical rain-forests.

- Shrub layer. This layer consists of bushes and low trees.

- Grass or grass with shrubbery.

- Moss or/and lichen.

- Forest litter. This layer consists of vegetation residues on a soil surface.

Properties of forest fuel [2] have great value for forecasting of forest fire danger. Socalled fuel models use for their description. Enough detailed characteristic of forest fuel types involved in process of surface forest fire is known. Plants and their residues of various level of decomposition are forest fuel in forest stand, which can burn at fires [3]. Practically all plants concern to combustible materials in forest biogeocenosis (live and dead, and also tree waste, fallen trees, litter, humus and peat horizons.

It is possible to consider three levels in forest fuel classification [4]:

\footnotetext{
${ }^{*}$ Corresponding author: firedanger@tpu.ru
} 
- Classification of elementary parts of forest fuel complexes, including separate plants from surface cover, shrub and undergrowth, low bushes, morphological parts of trees (branches, snags, dead fallen wood etc).

- Classification of simple complexes (forest fuel layers) inside biogeocenosis.

- Classification of biogeocenosis as multiple forest fuel complexes.

Forest fuel segmentation of all layers into groups is considered in classification of N.P. Kurbatskiy $[5,6]$ not only using their place in biogeocenosis, but also and function carried out by them during fire. All forest fuel separated in next groups [5]: 1) burning conductors, 2) sustaining combustion, 3) inhibitory burning.

The purpose of the present work is mathematical modeling of heat transfer processes in separate morphological part of grass vegetation at influence of radiation from front of surface forest fire.

\section{Physical and Mathematical Statements}

The mathematical model is developed taking into account following suppositions. The separate morphological part of grass plant (for definiteness - caulis) is considered. The caulis of blade is considered only without presence of lamina. The caulis is considered as three-layer structure that consists of internal cavity, pulp and protective layer [7].

The basic assumptions are resulted:

1. Short-term influence of a radiant thermal flux from surface forest fire front (fire of low intensity) is considered during the period previous possible ignition of blade.

2. The three-layer system (structure) of blade caulis with effective thermophysical characteristics is considered.

3. It is supposed, that caulis thermophysical characteristics do not depend on temperature.

4. Thermal decomposition of caulis tissues under the influence of the raised temperatures is neglected.

5. Evaporation of cellular moisture from caulis tissues also is neglected.

6. Conduction is basic mechanism of heat transfer in caulis tissues.

7. The monolithic structure of caulis tissues is considered.

Geometry of decision area is described on fig. 1.

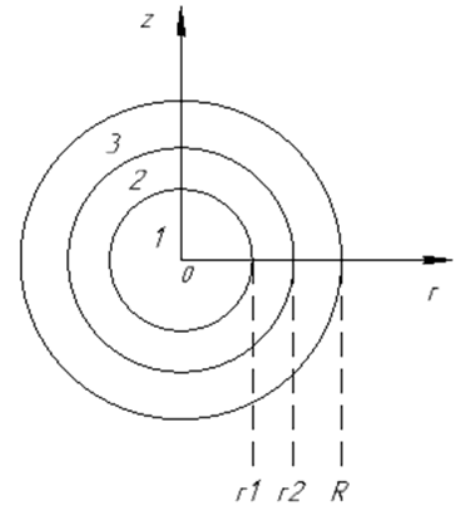

Fig. 1. The scheme of decision area.

Processes of heat transfer in layered structure of blade caulis till the moment of possible ignition are described by the non-stationary differential equations of heat conductivity with corresponding initial and boundary conditions: 


$$
\begin{aligned}
& \rho_{1} c_{1} \frac{\partial T_{1}}{\partial t}=\frac{\lambda_{1}}{r} \frac{\partial}{\partial r}\left(r \frac{\partial T_{1}}{\partial r}\right)+\lambda_{1} \frac{\partial^{2} T_{1}}{\partial z^{2}} \\
& \rho_{2} c_{2} \frac{\partial T_{2}}{\partial t}=\frac{\lambda_{2}}{r} \frac{\partial}{\partial r}\left(r \frac{\partial T_{2}}{\partial r}\right)+\lambda_{2} \frac{\partial^{2} T_{2}}{\partial z^{2}} \\
& \rho_{3} c_{3} \frac{\partial T_{3}}{\partial t}=\frac{\lambda_{3}}{r} \frac{\partial}{\partial r}\left(r \frac{\partial T_{3}}{\partial r}\right)+\lambda_{3} \frac{\partial^{2} T_{3}}{\partial z^{2}} \\
& \left.T_{i}\right|_{t=0}=T_{i 0}, \\
& r=R,-\lambda_{3} \frac{\partial T_{3}}{\partial r}=q_{f f}, \\
& r=0,-\lambda_{1} \frac{\partial T_{1}}{\partial r}=0, \\
& z=H,-\lambda_{i} \frac{\partial T_{i}}{\partial z}=0, \\
& z=R 1,-\lambda_{i} \frac{\partial T_{i}}{\partial z}=0, \\
& r=R 1,-\lambda_{1} \frac{\partial T_{1}}{\partial r}=-\lambda_{2} \frac{\partial T_{2}}{\partial r}, T_{1}=T_{2}, \\
& r=R 2,-\lambda_{2} \frac{\partial T_{2}}{\partial r}=-\lambda_{3} \frac{\partial T_{3}}{\partial r}, T_{2}=T_{3},
\end{aligned}
$$

Where $T_{i}, \rho_{i}, c_{i}, \lambda_{i}$ - temperature, density, thermal capacity and heat conductivity of layers of blade caulis ( 1 - air cavity, 2 - pulp, 3 - protective layern). r, z - cylindrical coordinates. $t$ - time coordinate. $q_{f f}$ - radiant thermal flux from forest fire front.

The problem is solved by a method of finite differences [8]. The multidimensional differential equations are solved by a locally-one-dimensional method [8].

\section{Results and Discussion}

Numerical realization of mathematical model for heat transfer in layered structure of caulis is carried out using programming language of high level Object Pascal. IBM PC compatible computer with Intel Pentium Core 2 Duo $3 \mathrm{GHz}$ processor unit and 8 GB RAM was used for computing experiments. The one-dimensional mathematical model allows to develop resource effective algorithm for program realization. Verification of onedimensional model is spent using flat statement in cylindrical coordinates in the present research. Typical temperature distribution in layered structure of caulis is presented for certain time moment on fig. 2 . 


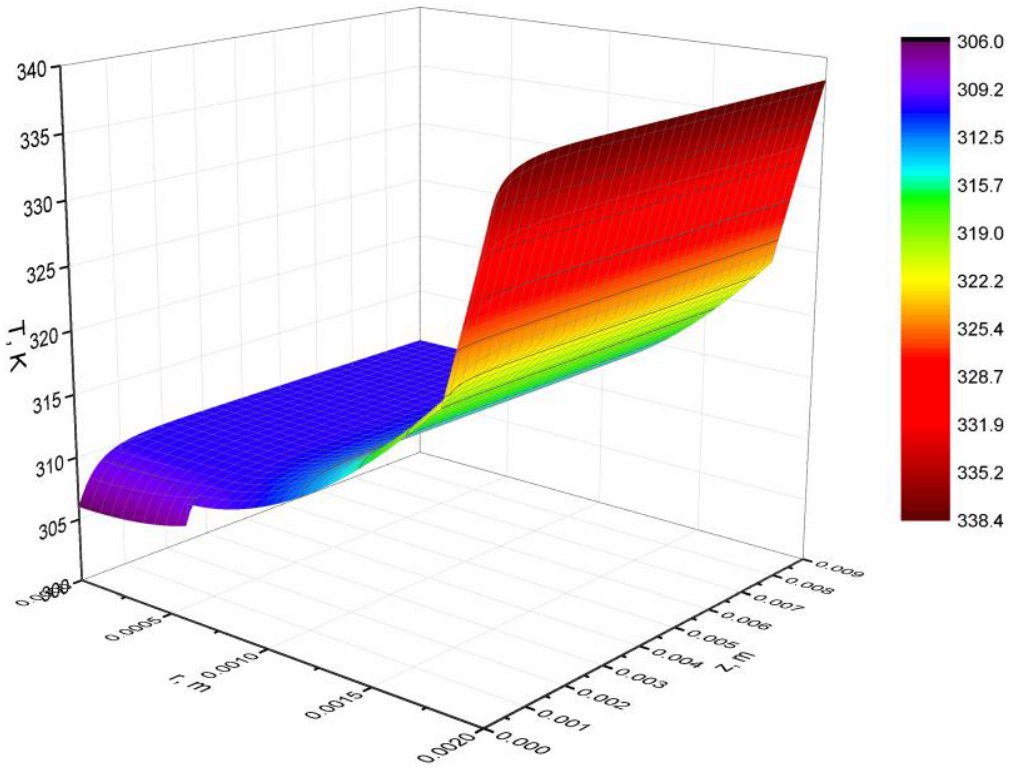

Fig. 2. Temperature distribution in caulis structure at influence of radiation from forest fire $\left(\mathrm{q}_{\mathrm{ff}}=7 \mathrm{~kW} / \mathrm{m}^{2}\right)$ at the moment of time $\mathrm{t}=3 \mathrm{~s}$.

Dependences of temperature in protective layer and pulp of caulis from time are presented on figs. 3,4 .

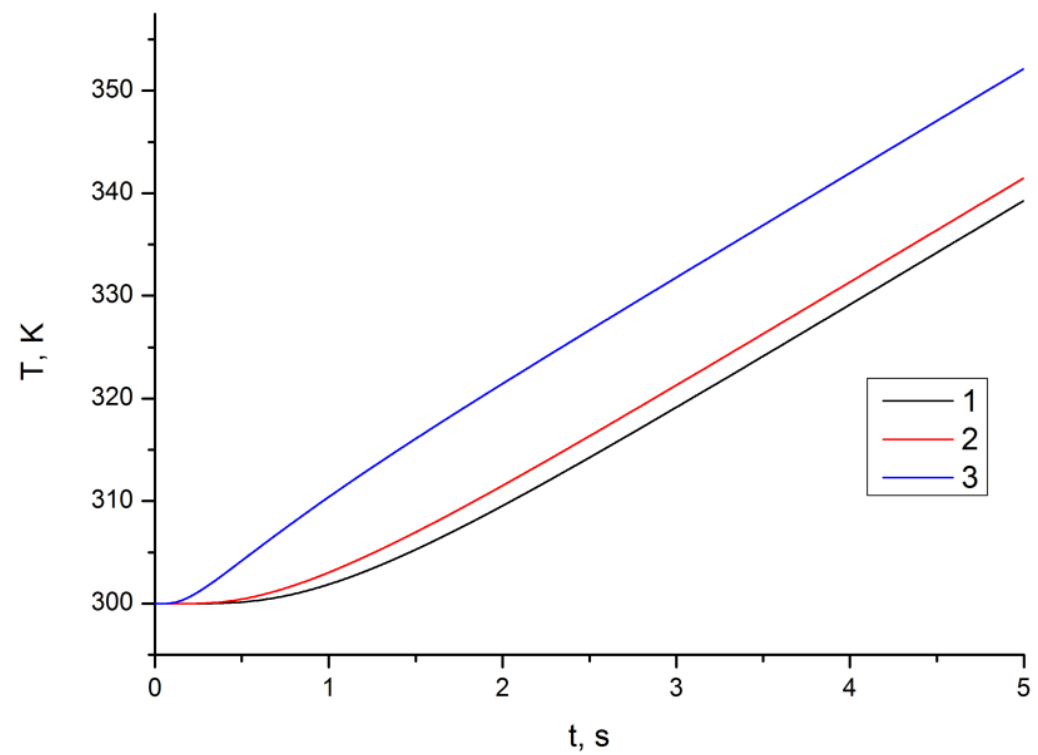

Fig. 3. Dependence of temperature on time in protective layer of caulis: $1-r=0.00185 \mathrm{~m}$, $2-\mathrm{r}=0.0019 \mathrm{~m}, 3-\mathrm{r}=0.00195 \mathrm{~m}$. 


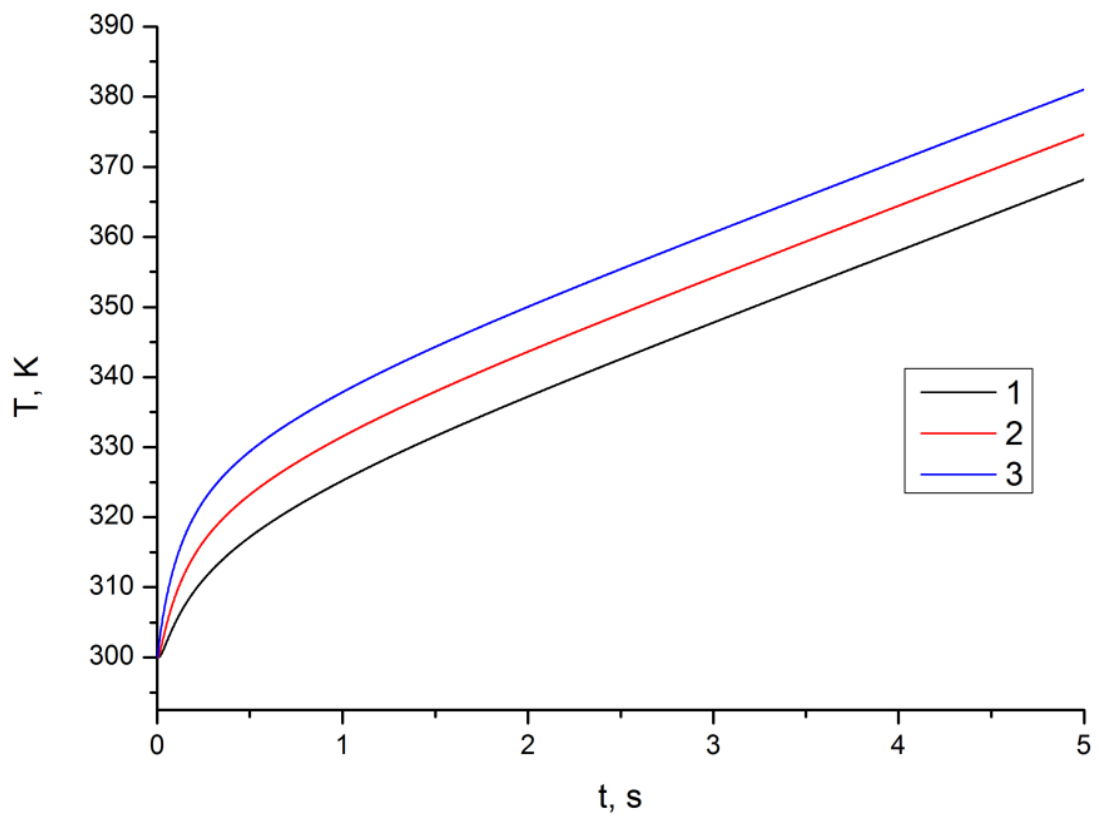

Fig. 4. Dependence of temperature on time in pulp of caulis: $1-r=0.0008 \mathrm{~m}, 2-r=0.001 \mathrm{~m}$, $3-\mathrm{r}=0.0015 \mathrm{~m}$.

The analysis of the obtained distributions allows making conclusion that there is an intensive warming up, both inside protective layer and pulp layer at influence of radiation from front of surface forest fire. Short-term influence of radiation from front of forest fire [9] (few seconds) on blade caulis was considered in the present work.

The preliminary analysis of heat transfer processes in layered structure of blade caulis shows, that it is necessary to use more perfect models for the full analysis of influence of radiation from forest fire front on morphological parts of plant. Such models should consider moisture evaporation from pulp and pyrolysis of dry organic substance [10-13]. However, using of thermophysical model for heat transfer simulation in caulis allows to make tentative estimations about time scales of ignition delay of plant at influence of a radiant thermal flux. Development of such mathematical models is necessary for creation of physically proved methods for an estimation of forest fire danger, pyrological estimations of surface cover in forest. Besides, such mathematical models can be used in information systems of biogeocenosis ecological monitoring.

\section{Conclusion}

The simple mathematical model of heat transfer in layered structure of blade caulis at influence of radiation from surface forest fire is presented in the current work. Results of the present research will allow to develop more perfect models for an estimation of forest fire danger and ecological consequences of forest fires. Furthermore, development of the complex deterministic-probabilistic approach for estimation of forest fires ecological 
consequences is possible taking into account prognostic modeling results of forest fire danger [14-15] and up-to-date information technologies [16-19].

\section{Acknowledgements}

Work was implemented under financial support of Russian Foundation for Basic Research. Grant N 16-41-700831.

\section{References}

1. V.I. Ufimtsev, O.A Kupriyanov, Strelnikov Bulletin KemGU 4, 8 (2013)

2. G.M. Byram, Combustion of forest fuels // Forest fire control and use (Ed. K.P. Davis, 1959)

3. N.P. Kurbatskiy, Questions of forest pyrology (1972)

4. A.V. Volokitina, M.A. Sofronov, Classification and mapping of vegetative combustible materials (2002)

5. N.P. Kurbatskiy, Questions of forest pyrology (1972)

6. N.P. Kurbatskiy, Technician and tactics of forest fire suppression (1962)

7. I.I. Andreeva, L.S. Rodman, Botany: studies for high schools (2005)

8. L. Vulkov, Lecture Notes in Computer Science 9045, 434 (2015)

9. N.V. Baranovskiy, Proceedings of SPIE 9680 (2015)

10. N.V. Baranovskiy, A.V. Zakharevich, D.S. Osotova, EPJ Web Conf. 82, 01020 (2015)

11. D. Mohan, C.U. Jr. Pittman, P.H. Steele, Energy and Fuels 20, 848 (2006)

12. G. Varhegyi, M.J. Antal, T. Szekely, P. Szabo, Energy and Fuels 3, 329 (1989)

13. R. Capart, L. Khezami, A.K. Burnham, Thermochimica Acta 417, 79 (2004)

14. E.P. Yankovich N.V. Baranovskiy, K.S. Yankovich, 9th International Forum on Strategic Technology, IFOST 2014, Paper 6991108 (2014)

15. G.V. Kuznetsov, N.V. Baranovsky, EPJ Web Conf, 76, 01028 (2014)

16. R.H. Fraser, Z. Li, Remote Sensing of Environment 82, 95 (2002)

17. Y.-H. Zhang, M. J. Wooster, O. Tutubalina, G. L. W. Perry, Remote Sensing and Environment 87, 1 (2003)

18. N.V. Baranovskiy, Cybernetics and Systems Analysis 51, 471 (2015)

19. N.V. Baranovskiy, E.P. Yankovich, Journal of Automation and Information Sciences 47, $11(2015)$ 